\title{
Investigation of PTMD System Affected by Parkfield Near-Field Earthquake
}

\author{
Ali Vatanshenas ${ }^{1}$ \\ ${ }^{1}$ Earthquake Engineering MSc student, Engineering Faculty, Islamic Azad University Central Tehran Branch, \\ Tehran, Iran \\ Correspondence: Earthquake Engineering MSc student, Engineering Faculty, Islamic Azad University Central \\ Tehran Branch, Tehran, Iran. E-mail: a.vatanshenas@gmail.com
}

Received: January 3, 2017

Accepted: February 17, 2017

Online Published: March 10, 2017

doi:10.5539/mas.v11n4p70

URL: http://doi.org/10.5539/mas.v11n4p70

\begin{abstract}
Earthquake is considered as the main destructive and collapsing factor of structures in near-fault zones, so design new structures and retrofitting existing structures in order to decrease structural responses is an unavoidable matter. One of the structural response reduction methods is using of TMDs. In this paper, a two-dimensional 10-storey steel structure as three structural models without PTMD, with a PTMD at the highest level and ten PTMDs with different characteristics at all levels with the Modal-FNA time-history analysis method under acceleration records with directivity and without directivity of Parkfield 2004 earthquake at the angle of the maximum acceleration response in the first mode period of structure after rotating the acceleration records at the station with directivity and its corresponding angle at the station without directivity were compared to each other in terms of the roof displacement, the input energy and the base shear. It was observed that the structure behavior in the case of using only one PTMD is better, but in the case where ten PTMDs with relative smaller masses were used compared to the case where only one PTMD was used is also with roof displacement reduction.
\end{abstract}

Keywords: earthquake directivity, near-field earthquake, Pendulum Tuned Mass Damper, tuned mass damper

\section{Introduction}

Nowadays, due to the low quality construction and control in developing countries and also the occurrence possibility of with directivity and pulse-type earthquakes in near-fault zones, retrofitting of existing structures is an undeniable priority. Furthermore, these structures are a place for comfort and convenience of people to live and work. Vibrations resulted from structural responses between $0.1 \mathrm{~g}$ to $0.25 \mathrm{~g}$ could disrupt the operation of the interested structure (Kareem, Kijewski, \& Tamura, 1999). Some sensitive people even feel small accelerations as 0.05g (Kareem et al., 1999). In this paper, the Pendulum Tuned Mass Damper (PTMD) system which is one of the common tuned mass dampers studied under the Parkfield 2004 with directivity earthquake at the most critical force applying angle. Other common TMD systems are: Translational TMD, Active TMD and Semi active TMD. The reasons of choosing PTMD compared to the other types are its simple preparation and installation cost, simplicity of adding to existing in operation structures without spending much time, proper performance, simple set up, the absence of any external actuator which reduces the initial cost of installation and maintenance, no need to apply energy to the system by the actuator and eliminating the possible delay in active tuned mass dampers (Kareem et al., 1999). The semi active system as shown in Figure 1 has both advantages of the active and passive systems. This system actively controls the stiffness and damping of the tuned mass damper with less need to the energy compared to the active system in Figure 2 (Nagarajaiah \& Varadarajan, 2005). But, the disadvantages of this system are complexity, initial costs, maintenance as well as being dependent to the external actuator. 


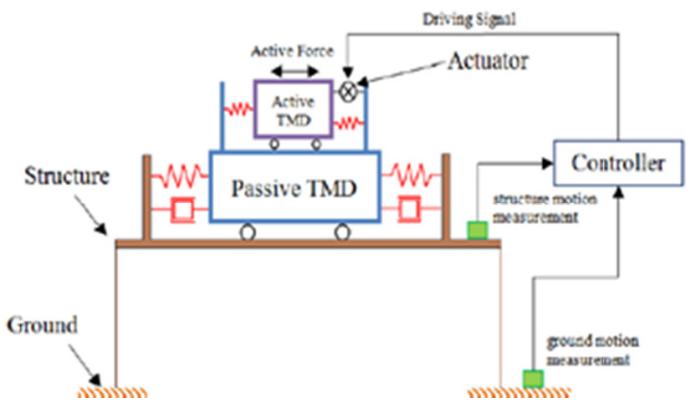

Figure 1. Semi active system

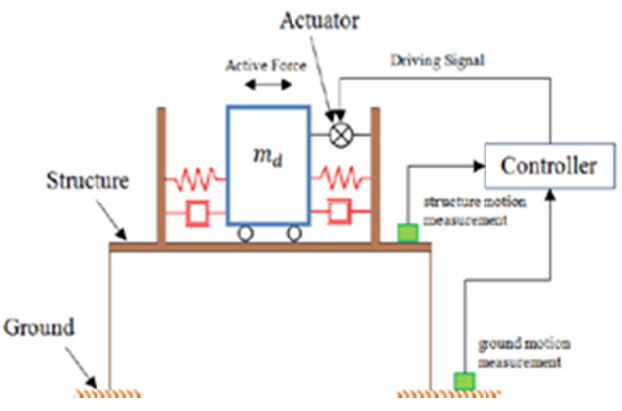

Figure 2. Active system

Two types of most common passive TMDs are PTMD and Translational TMD (Conner, 2003). For small angular variations, PTMD in Figure 3 and Translational TMD in Figure 4 show similar behavior and can be modeled with equal stiffness and damping ratio. Hence, the design method is the same for both systems (Conner, 2003). As shown in Figure 3 and Figure 4, one of the advantages of PTMDs compared to Translational TMDs is the absence of any support or bearings (Conner, 2003). Based on the support conditions, the PTMD efficiency due to its less friction is more than Translational TMD and also the structure which is used as support in Translational TMDs causes increasing of economic costs. The Taipei 101 building in Taiwan represented in Figure 5 with a height of 508m above the ground surface has three TMDs which one of them is a PTMD with a weight of 660 tons (Tamboli, Joseph, Vadnere, \& Xu, 2008).

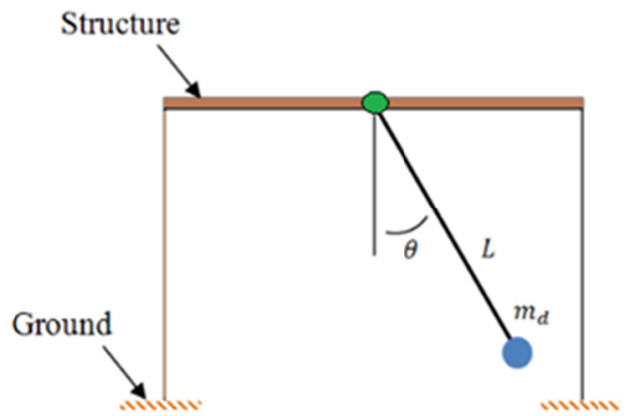

Figure 3. PTMD system

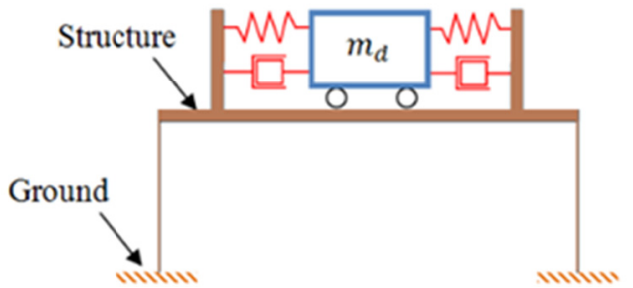

Figure 4. Translational TMD system

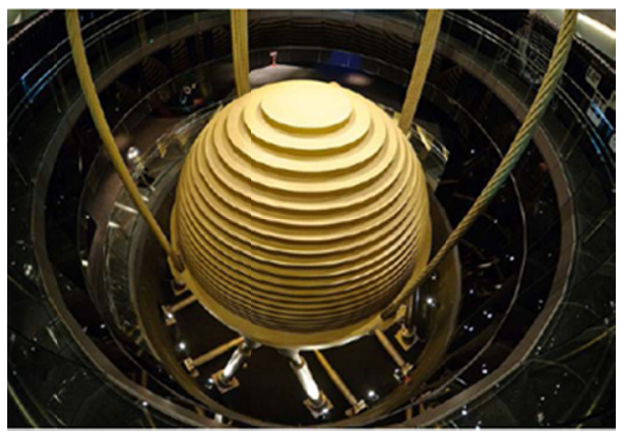

Figure 5. Taipei 101 building

Loads caused by earthquakes are mostly random and involve a greater number of natural frequencies of the structure (Chen \& Wu, 2001). Often, using only one passive TMD system is not enough for controlling displacements of the structure under seismic loads (Clark, 1988). TMDs should be adjusted based on the natural frequency of the structure, so that when the structure starts to vibrate by the influence of the external force, TMDs with phase difference start to resonate with respect to the connection point to the structure (Setareh, Ritchey, Baxter, \& Murray, 2006).

\section{Determination of Acceleration Records Applied to Structure}

Two near-fault stations of Parkfield earthquake 2004 with a distance of $10 \mathrm{~km}$ from the earthquake epicenter as 
shown in Figure 6 are located at two sides of the earthquake epicenter are considered, which one of them (Parkfield - Fault Zone 1) is at the directivity side and the other one (Parkfield - Fault Zone 7) at the without directivity side. By investigating the shear wave velocity at a depth of $30 \mathrm{~m}$ (for stations Parkfield - Fault Zone 1 and Parkfield-Fault Zone 7 are $178.27 \mathrm{~m} / \mathrm{sec}$ and $297.46 \mathrm{~m} / \mathrm{sec}$, respectively) the soil type for both stations is the same (soil type III) according to the Iranian code of Practice for seismic resistant design of buildings standard No.2800, (2015). The magnitude of the recorded earthquake for both stations is 6 on the Richter scale. The fault mechanism for both stations is strike slip and according to the mentioned above conditions the comparison of the results obtained from these stations is possible because they are in the same conditions in terms of the magnitude, the distance from the earthquake epicenter, the soil type and the fault mechanism.

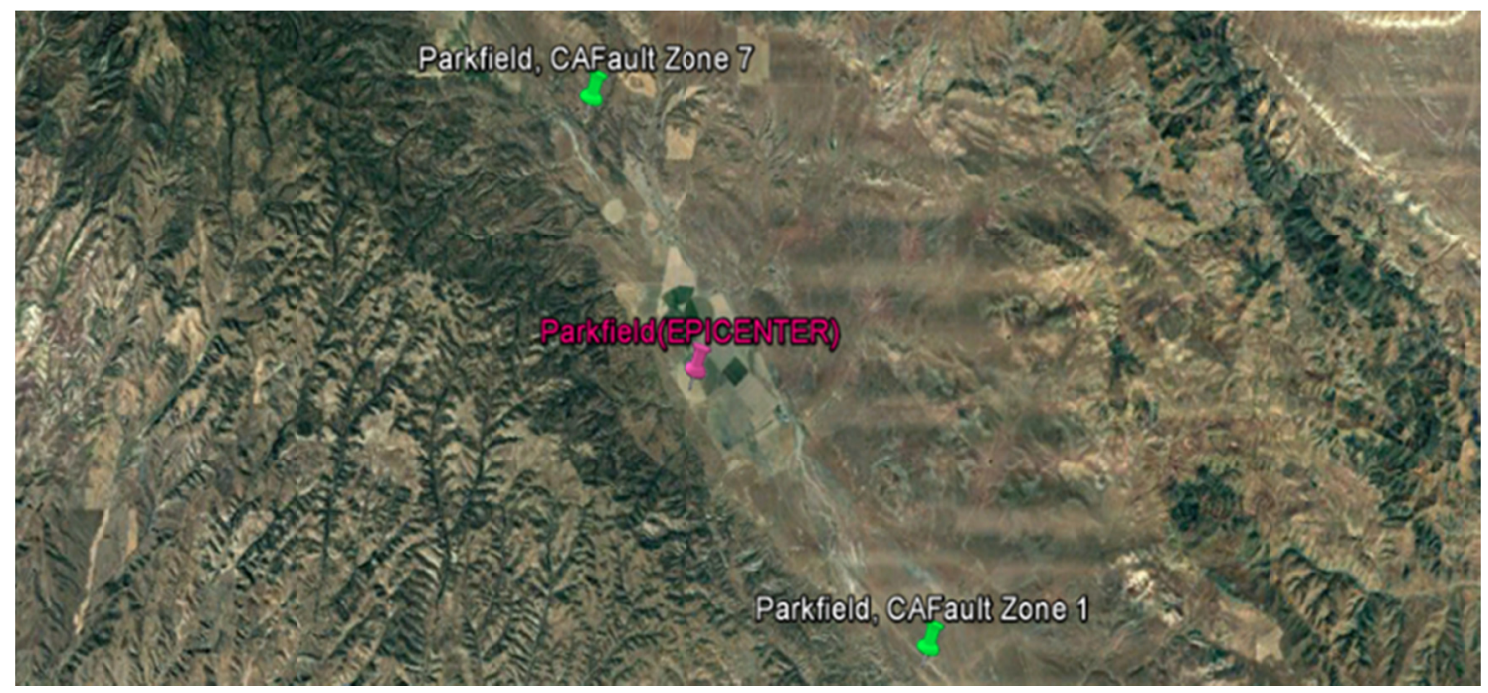

Figure 6. Two near-fault stations of Parkfield earthquake 2004

Now, the response acceleration-period graph represented in Figure 7 is drawn for the horizontal acceleration records at the station with directivity after rotating the acceleration records by the rotation matrix in equation (1). It is observed in Figure 7 that the maximum value at the first mode period of the studied structure $\mathrm{T}=1.64 \mathrm{~s}$ occurred after $\alpha=40^{\circ}$ rotation of the recorded 0 degree at the angle of $40^{\circ}$ which indicates the angle that we applied the acceleration records at it as shown in Figure 8, and also 0 degree acceleration records recorded at the station without directivity are rotated to $\alpha=40^{\circ}$ as shown in Figure 9 and applied to the structure as the acceleration records without directivity.

$$
\mathrm{R}=\left[\begin{array}{cc}
\cos (\alpha) & -\sin (\alpha) \\
\sin (\alpha) & \cos (\alpha)
\end{array}\right]
$$

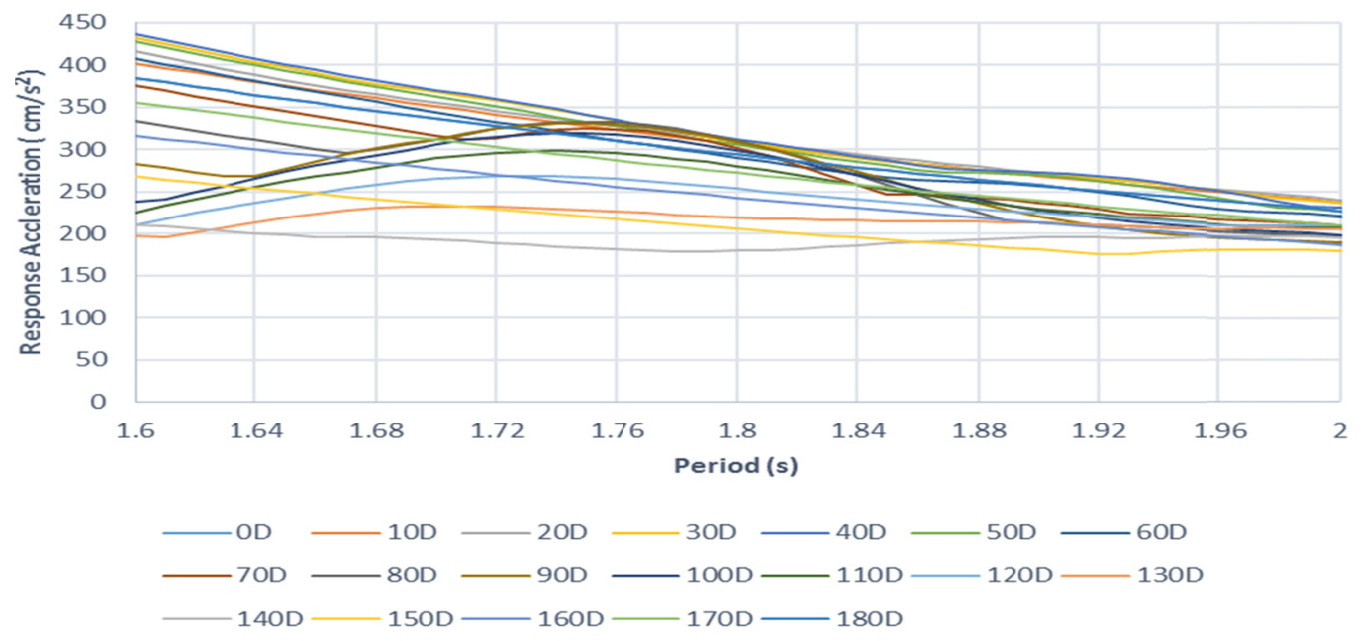

Figure 7. the response acceleration-period graph at the station with directivity after rotating the acceleration records by the rotation matrix $\mathrm{R}$ 


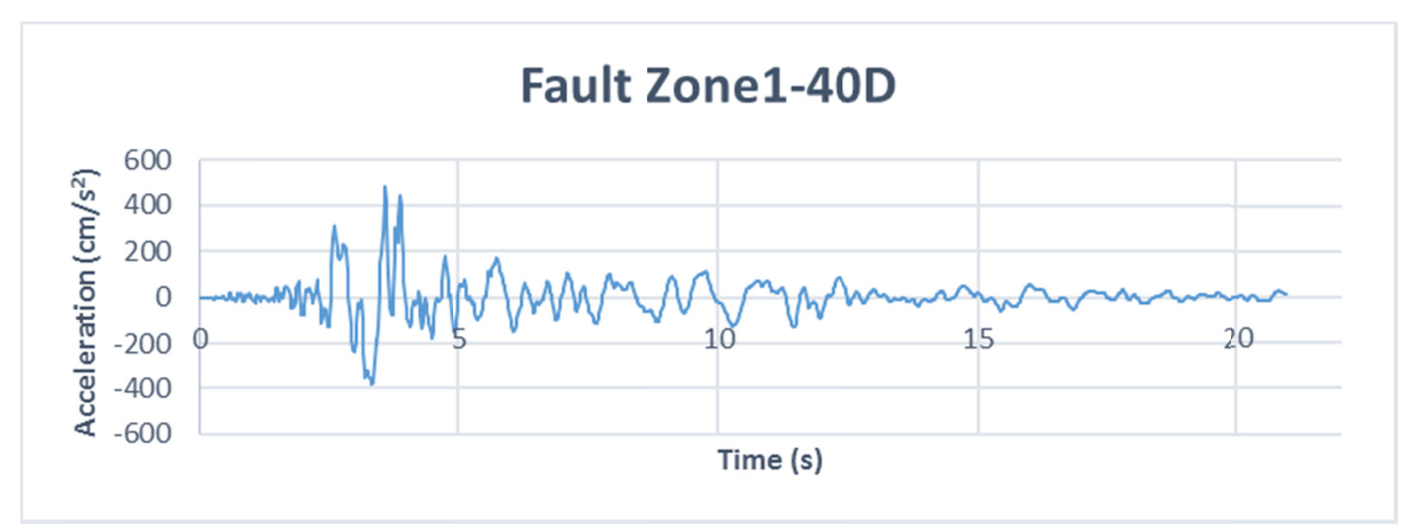

Figure 8 . With directivity acceleration applied to the structure

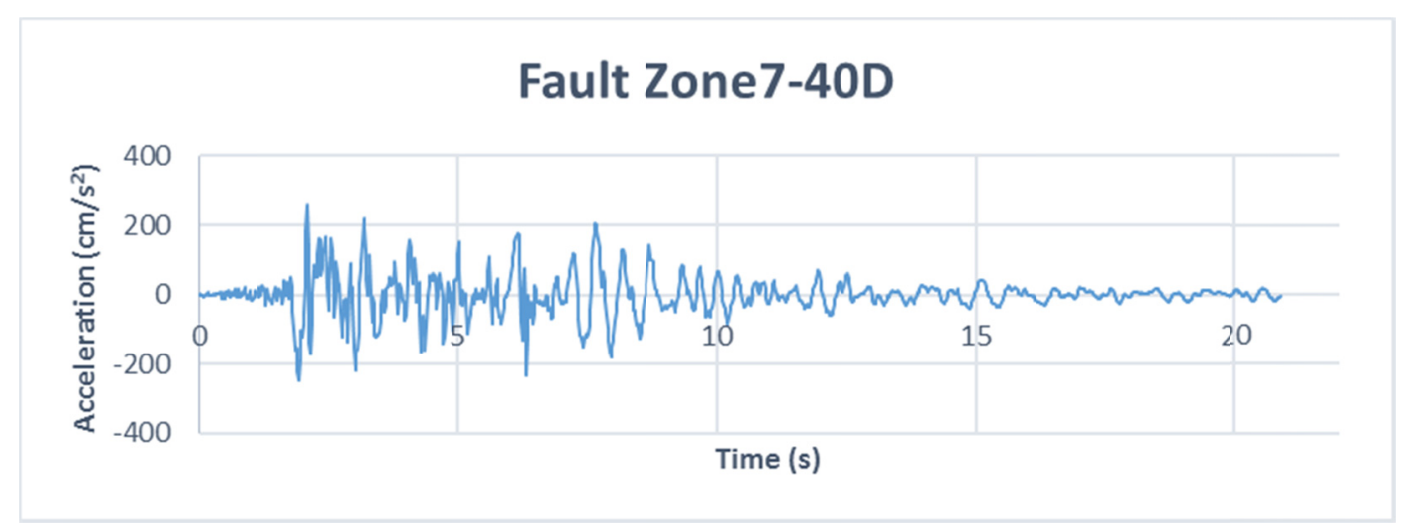

Figure 9. Without directivity acceleration applied to the structure

\section{Determination of Relationships and Characteristics of PTMD}

The equation of the free vibration motion of the pendulum shown in Figure 10 under the initial conditions is as equation (2), where $\mathrm{I}_{\mathrm{ZZA}}$ is the moment of inertia of the pendulum mass around point $\mathrm{A}, \mathrm{C}$ is the pendulum damping, $\mathrm{m}$ is the pendulum mass equal to 0.1 of the structure mass (assuming the rod without mass) and $\mathrm{D}$ is the distance between the pendulum mass center and Point A.

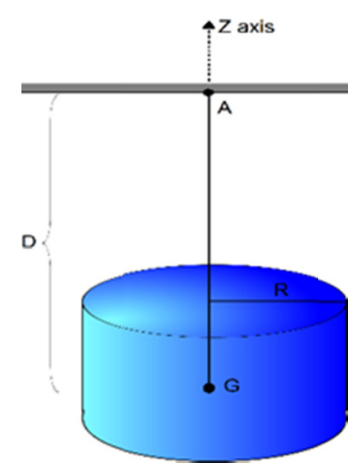

Figure 10. Pendulum considered in this study

$$
\mathrm{I}_{\mathrm{zzA}} \ddot{\theta}+\mathrm{C} \dot{\theta}+m g D \operatorname{Sin} \theta=0
$$

The equation of motion for each pendulum without considering the damping in order to obtain the natural angular frequency of the pendulum is as equation (3). This equation is a non-linear expression and could be considered as linear for small angles with a good approximation by equation (4) and obtain the pendulum natural frequency as equation (5), where $\omega_{n}$ is the natural angular frequency of the system.

$$
\mathrm{I}_{\mathrm{zzA}} \ddot{\theta}+m g D \operatorname{Sin} \theta=0
$$




$$
\begin{aligned}
& \mathrm{I}_{\mathrm{zzA}} \ddot{\theta}+m g D \theta=0 \\
& \omega_{\mathrm{n}}=\sqrt{\frac{\mathrm{mgD}}{\mathrm{I}_{\mathrm{zzA}}}}
\end{aligned}
$$

Then, as the structure and the pendulum should have the same angular frequency to adjust PTMD, therefore the damped angular frequency resulted from the time history analysis by the Modal-FNA method is considered equal to the damped angular frequency of the pendulum by assuming the structure damping ratio equal to 5 percent. By substituting equation (5) into equation (6) where $\omega_{\mathrm{d}}$ is the damped angular frequency, a relationship for the pendulum length is obtained which depends on the mass moment of inertia $\mathrm{I}_{\mathrm{ZZA}}$, the damped angular frequency, the pendulum weight and the damping ratio $\xi$ by equation (7). Since the mass moment of inertia for the cylinder around its central axis is equal to $\mathrm{I}_{\mathrm{ZZA}}=\mathrm{MR} / 2$, by substituting this value into equation (7), and by assuming the damping ratio for each mode as constant, the damped angular frequency is a unique value, hence the ratio of $\mu$ for each mode is a constant value. Then, equation (8) is obtained. This formula assists architects to determine the user space occupation amount which is the disadvantage of the PTMD system based on their desire, because as long as equation (8) works for certain values of the pendulum length and the cylinder radius, the damped angular frequency does not change.

$$
\begin{aligned}
\omega_{\mathrm{d}} & =\omega_{\mathrm{n}} \sqrt{1-\xi^{2}} \\
\mathrm{D} & =\frac{\mathrm{I}_{\mathrm{zzA}} \omega_{\mathrm{d}}^{2}}{\mathrm{mg}\left(1-\xi^{2}\right)} \\
\mathrm{D} & =\mu \mathrm{R}^{2}
\end{aligned}
$$

\section{Discussion}

By assuming that the pendulum displacement due to the initial displacement and velocity is at the damping conditions similar to Figure 11, X (t) is calculated by equation (9) where ø is the phase angle and $\xi$ is calculated by equation (10) with a good approximation. In this paper, we intend to use a pendulum that after 5 cycles its response reaches to 10 percent of its peak value, hence equation (10) turns into the simple equation (11) in which $\mathrm{n}_{10 \%}$ is the number of cycles which takes long that the pendulum response reaches to 10 percent of its peak value. This relationship yields the damping ratio value equal to $\xi=0.0732$. Therefore, the $\mathrm{C}$ damping is also obtained from equation (12) and The system stiffness is calculated by equation (13).

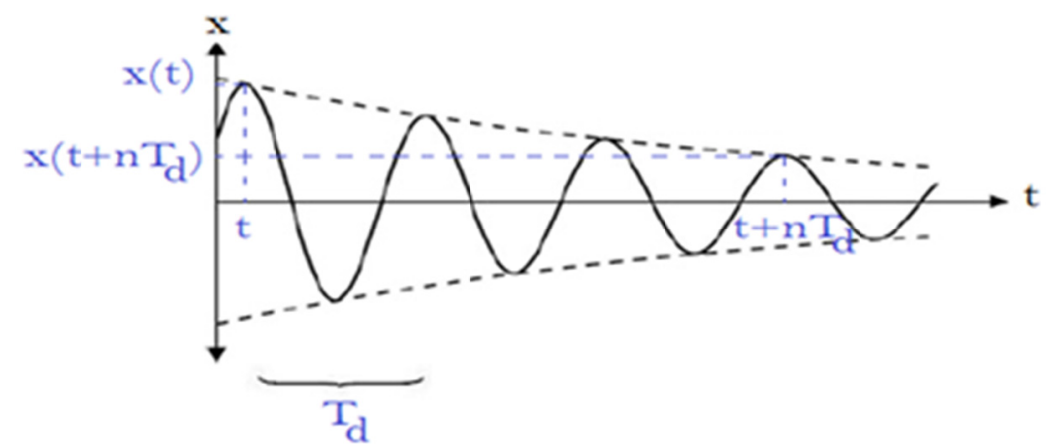

Figure 11. Pendulum displacement due to the initial conditions

$$
\begin{aligned}
\mathrm{X}(\mathrm{t}) & =A \mathrm{e}^{-\xi \omega_{\mathrm{n}}} \cos \left(\omega_{\mathrm{d}} t-\phi\right) \\
\xi & =\frac{\ln \frac{\mathrm{x}(\mathrm{t})}{x\left(t+n \mathrm{~T}_{\mathrm{d}}\right)}}{2 \Pi \mathrm{n}} \\
\xi & =\frac{0.366}{\mathrm{n}_{10 \%}} \\
C & =2 \xi \mathrm{m} \omega_{\mathrm{n}} \\
\mathrm{K} & =\frac{\mathrm{m} \omega_{\mathrm{d}}^{2}}{1-\xi^{2}}
\end{aligned}
$$

The studied structure in this paper is a two-dimensional 10-storey steel structure with three spans with special steel moment frame as shown in Figure 12. According to the mentioned relationships above we use PTMDs with a length of $\mathrm{D}=0.75 \mathrm{~m}$ and the radius of $\mathrm{R}=1 \mathrm{~m}$. In the following, three structure models are investigated. In model 
number 1, the structure is assumed without PTMD, in model number 2 the whole mass of PTMD is put at the $10^{\text {th }}$ level (PTMD (II)) and in model number 3 the PTMD mass is divided between all levels (PTMD1 to PTMD10) with respect to the levels lateral displacements under the earthquake force based on the Iranian code of Practice for seismic resistant design of buildings standard No.2800 (2015), and applied the acceleration records with directivity and without directivity to each three models. In Table 1 the damping and stiffness of the used PTMDs are presented. These three models are compared to each other in terms of the roof displacement, input energy to the structure and the base shear.

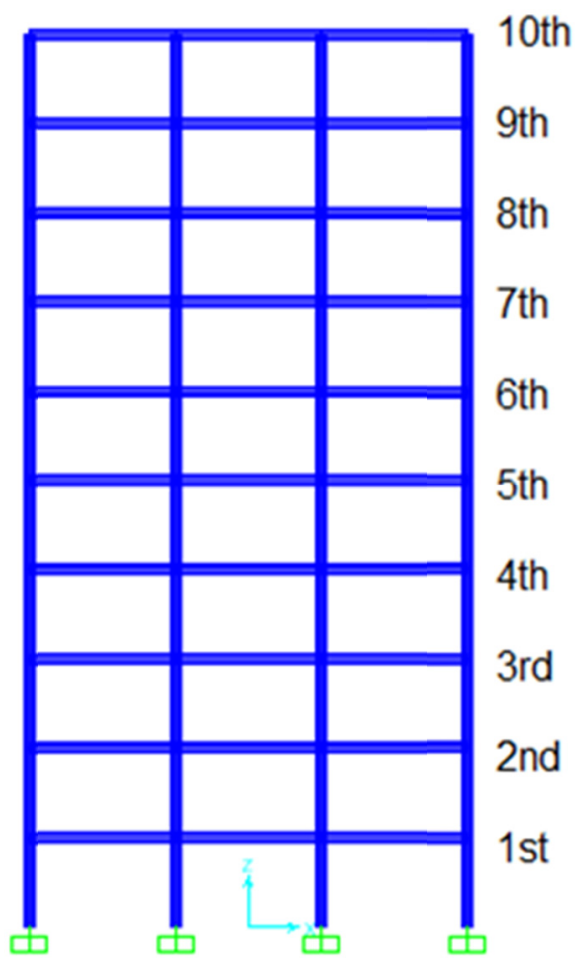

Figure 12.2D structure used in this study

Table 1. Damping and stiffness of PTMDs

\begin{tabular}{llll}
\hline Name & Model & $\mathrm{C}(\mathrm{Kg} / \mathrm{Sec})$ & $\mathrm{K}\left(\mathrm{Kg} / \mathrm{Sec}^{2}\right)$ \\
\hline PTMD(II) & II & 1354.96 & 348683.8 \\
PTMD10 & III & 224.772 & 57840.92 \\
PTMD9 & III & 214.882 & 55295.83 \\
PTMD8 & III & 200.472 & 51587.73 \\
PTMD7 & III & 181.222 & 46634.11 \\
PTMD6 & III & 157.65 & 40568.79 \\
PTMD5 & III & 130.55 & 33594.72 \\
PTMD4 & III & 100.867 & 25956.152 \\
PTMD3 & III & 69.805 & 17963.111 \\
PTMD2 & III & 39.25 & 10100.219 \\
PTMD1 & III & 12.975 & 3338.9748 \\
\hline
\end{tabular}

\section{Comparison Based on Roof Displacement}

According to Figure 13 and Figure 14 which are related to the cases of acceleration records with directivity and acceleration records without directivity, respectively it is observed that the best case in terms of the roof displacement in both cases including with and without directivity is the second model in which the whole mass of PTMD is placed at the $10^{\text {th }}$ level and causes a significant reduction in the roof displacement. Also in the third model, in most of the time history the roof displacement shows a suitable behavior in the case that acceleration records with directivity are applied to the structure compared to the case without PTMD and decreases the roof displacement, but in some times increases the roof displacement compared to the initial model. However, 
throughout the displacement time history in the case that acceleration records without directivity are applied to the structure, the third model decreases the roof displacement compared to the initial model. It could also be understood that as we go towards the end of the time history, the PTMD effect on the roof displacement is more than the initial moments of the earthquake force applying to the structure and it is also observed that as we go towards the end of the roof displacement time history, this decreasing effect resulted from PTMDs in the second and third models get close to each other.

\section{FAULT ZONE1-40D}

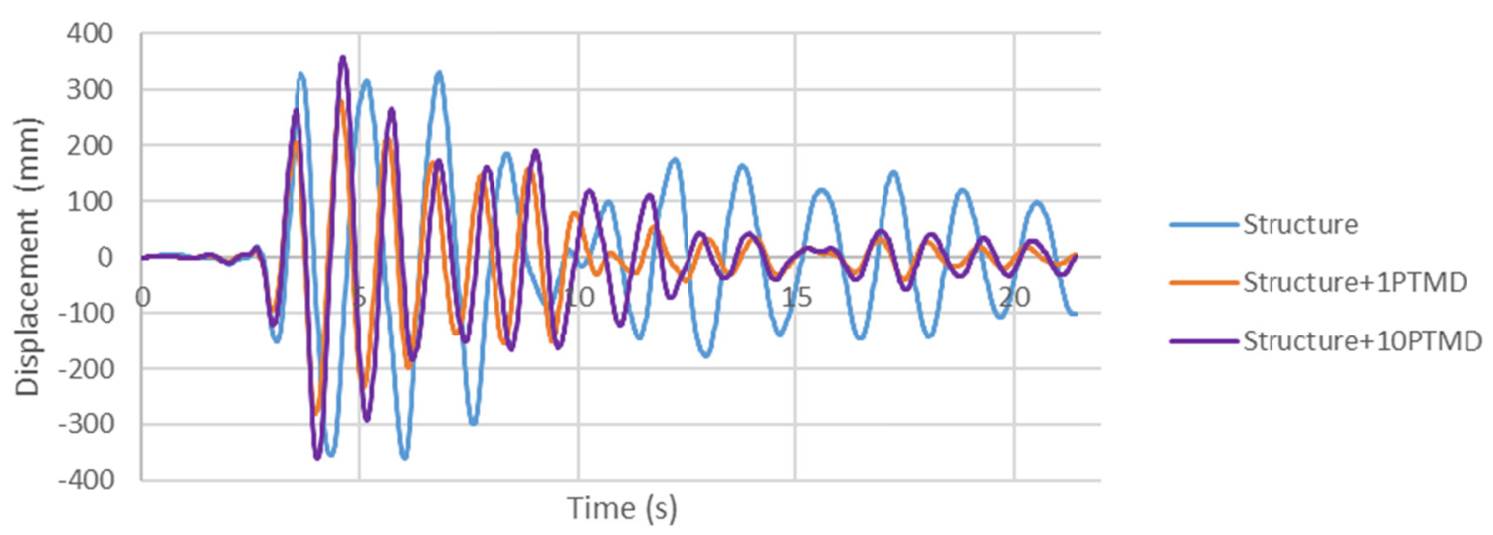

Figure 13. Roof displacement due to with directivity acceleration records

FAULT ZONE7-40D

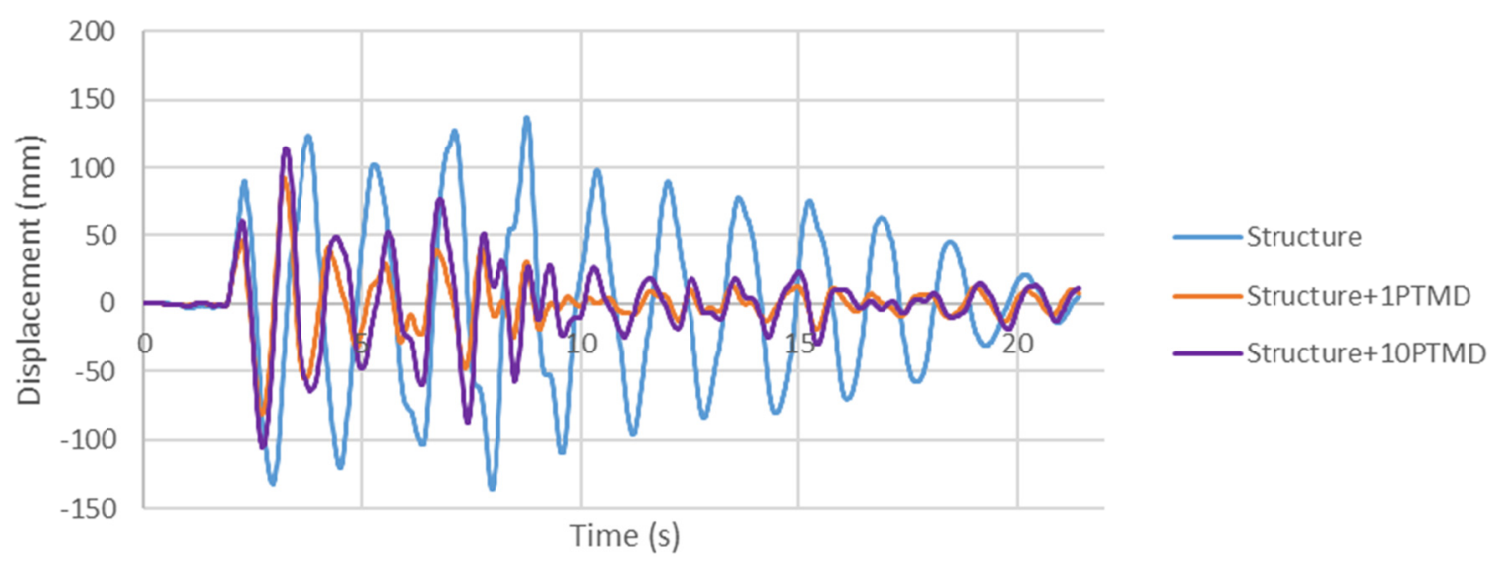

Figure 14. Roof displacement due to without directivity acceleration records

\section{Comparison Based on Input Energy}

Using the PTMD system in the structure compared to the initial structure causes increasing of stiffness and decreasing the structure period which is because of the structure characteristics and does not depend on the earthquake force and leads to increase the input energy to the structure. As shown in Figure 15 which is about the case of acceleration records with directivity, it is observed that throughout the earthquake occurrence time the maximum input energy is related to the second model which includes a structure with a PTMD located at the $10^{\text {th }}$ level and indicated the maximum value of the structure stiffness compared to two other models. In Figure 16 which is about the case of acceleration records without directivity, it is observed that in moments that the maximum value of the acceleration is applied to the structure as shown in Figure 9 the input energy of the structure is less than two other models, but as we go towards the end of the time history of the earthquake which is accompanied by decreasing the acceleration applied to the structure, the structure input energy increases compared to two other models and also as shown in Figure 16 in most times during the earthquake the input energy value of the third model is more than the second one. 


\section{FAULT ZONE1-40D}

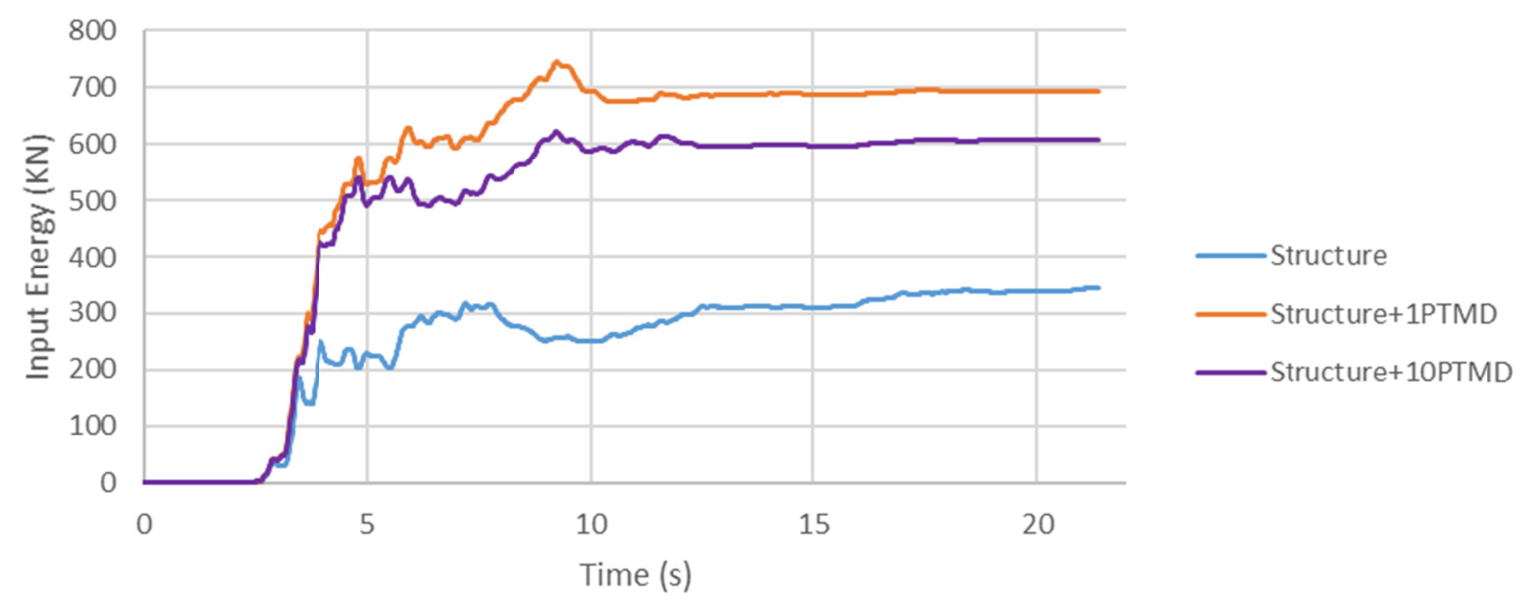

Figure 15. Input energy due to with directivity acceleration records

FAULT ZONE7-40D

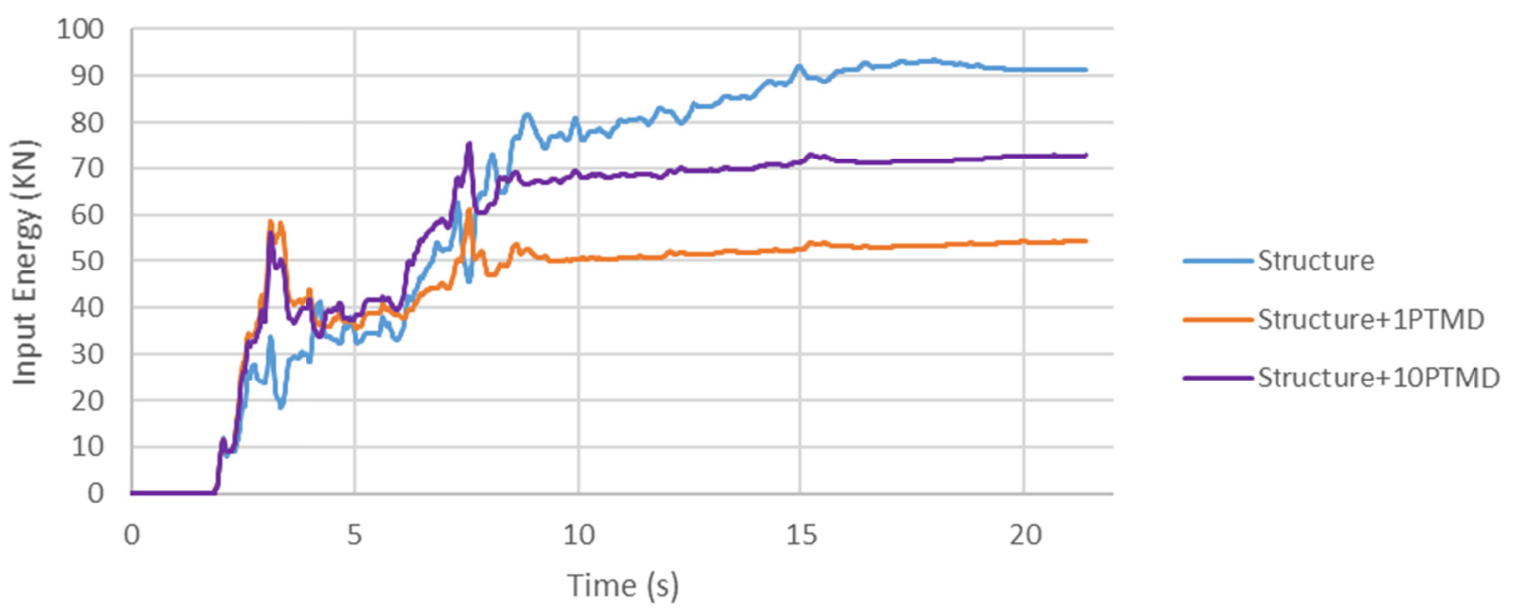

Figure 16. Input energy due to without directivity acceleration records

\section{Comparison Based on Base Shear}

The changing trend of the base shear is almost similar to the trend of observed in the input energy changes. According to Figure 17 and Figure 18 which are about the cases of acceleration records with directivity and acceleration records without directivity, it is observed that in Figure 17 that the maximum value of the shear force applied to the structure is related to the second model which causes the maximum stiffness increasing in the structure compared to two other models. The third model also causes increasing the base shear, but in most cases this increase is less than the values obtained by the second model and the initial structure almost has the minimum base shear at almost all moments and it is also observed that as we approach to the end time of the earthquake occurrence the differences of the base shear between three provided models decrease significantly. But in Figure 18 conditions are different and at the beginning of the earthquake which the values of the acceleration applied to the structure are greater, the base shear of the initial structure is less than two other models, but as we approach to the end of the earthquake time which is accompanied by decreasing of the values of accelerations applied to the structure, the base shear obtained from the initial structure increases compared to two other models and it is also observed that the values of the second and third models are very close to each other at the final cycles of the earthquake. 


\section{FAULT ZONE1-40D}

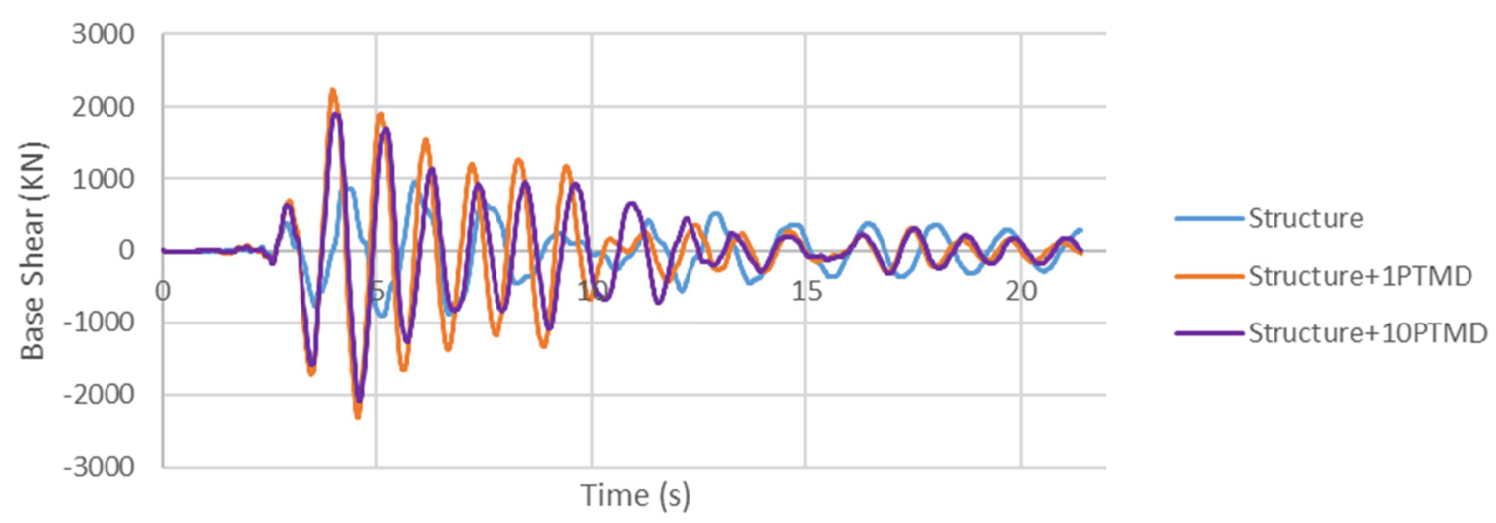

Figure 17. Base shear due to without directivity acceleration records

\section{FAULT ZONE7-40D}

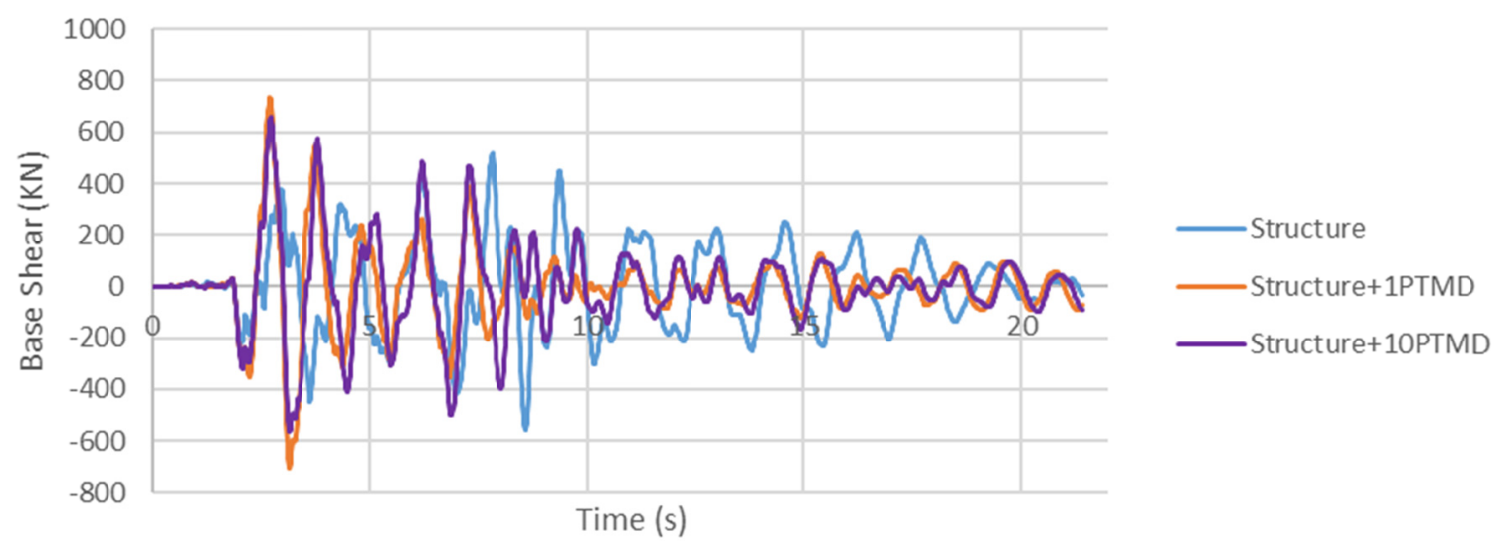

Figure 18. Base shear due to without directivity acceleration records

\section{Conclusions}

In this paper, three structure models including without PTMD, with a PTMD at the highest level and ten PTMDs at all levels were compared to each other. Comparison of these three models in terms of the roof displacement, the input energy and the base shear in both cases of acceleration records with directivity and without directivity, showed that the model with a PTMD shows a better behavior in terms of the roof displacement decrease, but sometimes for placing a large mass on a span of a specific level we encounter problems especially in the retrofitting context which this mass has not been considered in the initial calculations and specific measures should be considered for this purpose. In such cases, to get relative good results for reducing the response of the roof displacement we could use the third model which is due to the use of lighter masses is more applicable for retrofitting purposes and also from this view that we have created more constraints to withstand against the earthquake instead of the second model. In both cases of acceleration records with directivity and without directivity, the maximum base shear applied to the structure increased after using PTMD in the structure compared to the initial structure which is due to the increase of the structure stiffness and also decreasing of the structure period.

\section{References}

Chen, G., \& Wu, J. (2001). Optimal Placement of Multiple Tuned Mass Dampers for Seismic Structures, Journal of Structural Engineering, 127(9), 1054-1062. http://doi.org/10.1061/(ASCE)0733-9445(2001)127:9(1054)

Clark, A. J. (1988). Multiple passive tuned mass dampers for reducing earthquake induced building motion, Proceedings of the $9^{\text {th }}$ world conference of earthquake engineering, Tokyo-Kyoto, Japan. 
Conner, J. J. (2003). Introduction to structural motion control ( $1^{\text {st }}$ ed.). United States: Prentice Hall. Iranian code of practice for seismic resistant design of buildings standard (4th ed.). (2015). Tehran: BHRC.

Kareem, A., Kijewski, T., \& Tamura, Y. (1999). Mitigation of Motion of Tall Buildings with Specific Examples of Recent Applications, Journal of Wind and Structures, 2(3), 201-251. http://doi.org/10.12989/was.1999.2.3.201

Nagarajaiah, S., \& Varadarajan, N. (2005). Short Time Fourier Transform Algorithm for Wind Response Control of Buildings with Variable Stiffness TMD. Journal of Engineering Structures, 27(3), 431-441. http://doi.org/10.1016/j.engstruct.2004.10.015

Setareh, M., Ritchey, J. K., Baxter, A. J., \& Murray, T. M. (2006). Pendulum Tuned Mass Dampers for Floor Vibration Control, Journal of Performance of Construction Facilities, 20(1), 64-73. http://doi.org/10.1061/(ASCE)0887-3828(2006)20:1(64)

Tamboli, A., Joseph, L., Vadnere, U., \& Xu, X. (2008). Sustainable Design Opportunities. Proceedings of CTBUH $8^{\text {th }}$ World Conference of Tall Buildings and Urban Habitat, Dubai.

\section{Copyrights}

Copyright for this article is retained by the author(s), with first publication rights granted to the journal.

This is an open-access article distributed under the terms and conditions of the Creative Commons Attribution license (http://creativecommons.org/licenses/by/4.0/). 